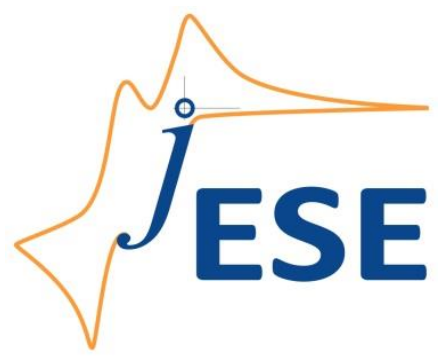

Open Access : : ISSN 1847-9286

www.jESE-online.org

Original scientific paper

\title{
Simultaneous electrochemical determination of acetaminophen and metoclopramide at electrochemically pre-treated disposable graphite pencil electrode
}

\author{
Shreekant M. Patil, Vijay P. Pattar, Sharanappa T. Nandibewoor
}

P. G. Department of Studies in Chemistry, Karnatak University, Dharwad 580003, India

${ }^{\square}$ Corresponding author: stnandibewoor@yahoo.com; Tel.: +91 836 2215286; Fax: +91 8362747884

Received: May 30, 2016; Revised: September 22, 2016; Accepted: September 26, 2016

\begin{abstract}
A sensitive and economic voltammetric method was developed for the simultaneous determination of acetaminophen (AMP) and metoclopramide (MCP) using pre-treated graphite pencil electrode (PTGPE). Compared to a graphite pencil electrode, the pretreated electrode showed an apparent shift of the oxidation potentials in the positive direction and a notable enhancement in the current responses for both AMP and MCP. Cyclic voltammetry (CV) was used to study the voltammetric behavior of the drugs, while differential pulse voltammetry (DPV) was used to determine AMP and MCP simultaneously. The dependence of the current on scan rate, $\mathrm{pH}$ and concentration was investigated to boost the experimental conditions for simultaneous determination. The calibration curves were obtained over the range of $0.1 \times 10^{-7}$ to $1.1 \times 10^{-7} \mathrm{M}$, the concentration of each of both the drugs was varied by keeping the other constant, and achieved lower detection limit of $3.25 \mathrm{nM}$ for AMP and $1.16 \mathrm{nM}$ for MCP. The developed method was found to be selective and rapid for the simultaneous determination of AMP and MCP. The proposed method was applied simultaneously in real samples and pharmaceutical samples, with satisfactory results.
\end{abstract}

\section{Keywords}

Acetaminophen, metoclopramide, voltammetry, graphite pencil electrode, analytical applications

\section{Introduction}

The development of a sensitive, simple, reliable and rapid method for the determination of analyte is of great importance. The pre-treated graphite pencil electrode (PTGPE) has been used as a biosensor in modern electroanalytical field due to its high mechanical rigidity, highly economical, good electrochemical reactivity, ease of modification, renewal of electrode and low background current $[1,2]$. PTGPE has good application in analysis of drugs, detection of traces of metal ions and 
neurotransmitters. Metoclopramide (4-amino-5-chloro-N-[2-(diethylamino)ethyl]-2-methoxybenzamide) (MCP) as shown in Scheme 1 has wide range of clinical applications in different fields such as gastroenterology, gynaecology, surgery, radiology and cardiology. It shows antiemetic and prokinetic properties in disorders of decreased gastrointestinal motility and it is a dopamine receptor antagonist which also plays very important role as active ingredient of many pharmaceutical formations related with the modification of digestive behavior. MCP hydrochloride is commonly used in prevention and relief of nausea and vomiting [3-4] but mainly used in combination with chemotherapy, where drugs such as cisplatin, and some cytotoxic agents, are highly emetic [5].
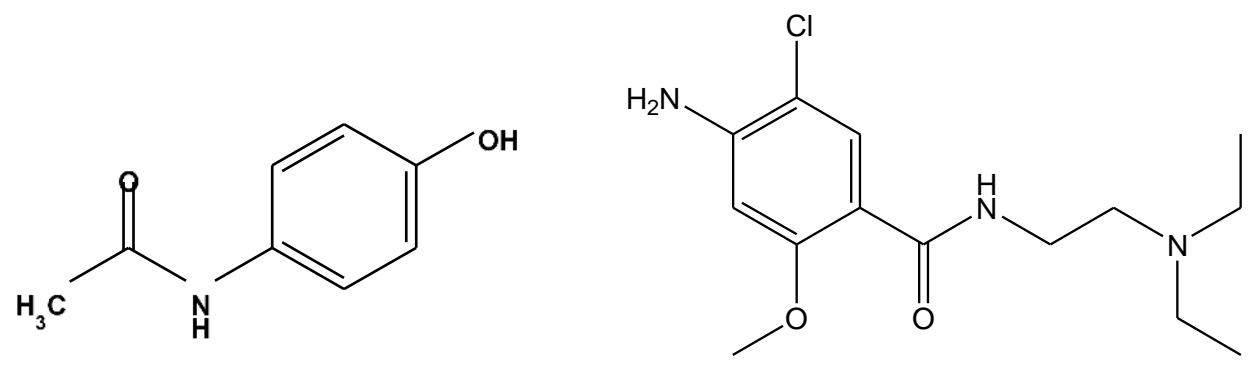

Scheme 1. Chemical structure of $A M P$ and $M C P$

Acetaminophen (AMP) (paracetamol, $\mathrm{N}$-acetyl-p-aminophenol) (Scheme 1) is a well-known drug which has extensive applications in pharma industries. It is a non-steroidal, antipyretic and antiinflammatory drug [6]. It is the preferred alternative to Aspirin, specifically for patients who cannot tolerate Aspirin [7] and its use is one of the common causes of poisoning worldwide [8] and analgesic compound that has high therapeutic value. It is also used as a precursor in penicillin and as stabilizing agent for hydrogen peroxide, photographic chemical, etc. [9]. At the recommended dosage, there are no side effects. However, overdoses of acetaminophen cause liver and kidney damage [10] and may lead to death. It is suspected that a metabolite of acetaminophen is the actual hepatotoxic agent [11].

Acetaminophen/metoclopramide hydrochloride is an oral fixed dose combination containing the analgesic acetaminophen and the antiemetic metoclopramide hydrochloride. The combination is used to treat the migraine symptoms, both to relieve headache and to treat associated nausea and vomiting (the antiemetic). In addition to its direct antiemetic effect, MCP also stimulates gastric emptying (prokinetic), which is often delayed during migraine attacks, and accelerates the absorption of AMP. The combination of AMP and MCP has shown to enhance the analgesia relief when used to treat the arthritis pain.

As MCP is always given with AMP in any formulations, it is important to determine both the components simultaneously. Allthough there are different methods of anlysis of AMP [12] and MCP [13] separately mentioned in the literature, only a few classical methods are available [14-18] for the simultaneous determination of these componds. In the present study, the electrochemical method, a very sensitive and selective method of analysis using newly functionalised PTGPE has been used in the determination of AMP and MCP simultaneously. The proposed method was applied in real samples and pharmaceuticals.

\section{Experimental aspects}

\section{Reagents and chemicals}

The pencil-lead rods (HB $5 \mathrm{~cm}$ length and $0.5 \mathrm{~mm}$ in diameter) were purchased from a local stationary. AMP and MCP were purchased from Sigma Aldrich, India. Stock solutions of AMP and 
MCP (1.0 mM) were freshly prepared in Millipore water. The phosphate buffer solutions (PBS) from $\mathrm{pH} 3.0$ to 11.2 were prepared according to the method of Christian and Purdy [19]. Other reagents used were of analytical grade. All other solutions were prepared with Millipore water.

\section{Instrumentation and analytical procedures}

The voltammetric experiments were carried out on a $\mathrm{CHI} 630 \mathrm{D}$ electrochemical analysing system ( $\mathrm{CH}$ instruments Inc., USA). The voltammetric experiments were carried out in a $10 \mathrm{ml}$ singlecompartment of three electrode glass cell with the reference electrode as silver electrode $(\mathrm{Ag} / \mathrm{AgCl})$, platinum as counter electrode and PTGPE as working electrode. $\mathrm{pH}$ measurements were carried with Elico LI120 pH meter (Elico Ltd., India). All experiments were performed at an ambient temperature of $298 \pm 0.2 \mathrm{~K}$.

The area of the electrode was obtained by the cyclic voltametric method using $1.0 \mathrm{mM} \mathrm{K}_{3} \mathrm{Fe}(\mathrm{CN})_{6}$ at different scan rates. For a reversible process, the following Randles-Sevcik formula was used [20].

$$
I_{\mathrm{p}}=0.4463\left(F^{3} / R T\right)^{1 / 2} n^{3 / 2} A_{0} D_{0}{ }^{1 / 2} C_{0} V^{1 / 2}
$$

where $I_{\mathrm{p}}$ refers to the anodic peak current, $A_{0}$ is the surface area of the electrode, $\mathrm{n}$ is number of electrons transferred, $v$ is the scan rate, $D_{0}$ is the diffusion coefficient and $C_{0}$ is the concentration of $\mathrm{K}_{3} \mathrm{Fe}(\mathrm{CN})_{6}$. For $1.0 \mathrm{mM} \mathrm{K}_{3} \mathrm{Fe}(\mathrm{CN})_{6}$ in $0.1 \mathrm{M} \mathrm{KCl}$ electrolyte, $T=298 \mathrm{~K}, R=8.314 \mathrm{~J} \mathrm{~K}^{-1} \mathrm{~mol}^{-1}, \mathrm{~F}=96,480$ Coulombs mol ${ }^{-1}, \mathrm{n}=1$, and $\mathrm{D}_{0}=7.6 \times 10^{-6} \mathrm{~cm}^{2} \mathrm{~s}^{-1}$; then from the slope of the plot of $\mathrm{I}_{\mathrm{p}}$ versus $\mathrm{v}^{1 / 2}$, relation, the surface area was calculated. In our experiment the slope was

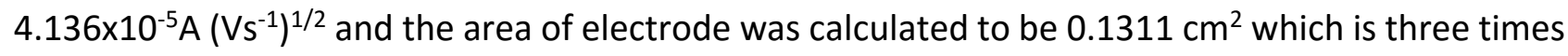
more than that of the GPE.

\section{Measurement procedure}

Stock solutions of $1 \mathrm{mM}$ of AMP and MCP were prepared by dissolving the desired amount in millipore water. Voltammograms were then recorded using voltammetric analyzer under the optimized parameters.

The parameters for DPV were, amplitude: $0.05 \mathrm{~V}$; initial potential: $0.0 \mathrm{~V}$; final potential: $1.4 \mathrm{~V}$; increase in potential: $0.004 \mathrm{~V}$; pulse width: $0.06 \mathrm{~s}$; sample width: quiet time: $2 \mathrm{~s}$; sensitivity: $1 \times 10^{-6} \mathrm{~A} \mathrm{~V}^{-1}$.

\section{Pre-treatment of electrode}

The electrochemical treatment of GPE was performed in different supporting electrolytes by potential cycling between $-2.0 \mathrm{~V}$ and $+2.0 \mathrm{~V}$ with a scan rate of $50 \mathrm{mV} \mathrm{s}{ }^{-1}$ for six scans. The investigated supporting electrolytes were each of $0.1 \mathrm{M} \mathrm{H}_{3} \mathrm{BO}_{3}, \mathrm{NaNO}_{3}, \mathrm{HClO}_{4}, \mathrm{H}_{2} \mathrm{SO}_{4}, \mathrm{H}_{3} \mathrm{PO}_{4}, \mathrm{HCl}$, $\mathrm{LiClO}_{4}$, and $\mathrm{Na}_{2} \mathrm{CO}_{3}$. The results showed that the GPE electrodes pretreated in $0.1 \mathrm{M} \mathrm{HCl}$ was the most selective and sensitive towards a AMP and MCP. So $0.1 \mathrm{M} \mathrm{HCl}$ was chosen for pre-treatment of electrodes. The prepared electrodes (PTGPE) were stored at room temperature in desiccators.

\section{Preparation of real and pharmaceutical samples}

The urine samples were collected from healthy humans and were diluted 100-fold with the phosphate buffer solution before analysis. Quantitative determination was performed by adding a standard solution of AMP and MCP to the detection system with the urine sample.

Metpar ${ }^{\circledR}$ tablets (Cipla, India) containing $500 \mathrm{mg}$ of acetaminophen and $5 \mathrm{mg}$ of metoclopramide were purchased from local pharmacy and were ground to a homogeneous fine powder in a mortar separately. A suitable amount of this powder was weighed and was treated with Millipore water for 20 minutes. The mixture was then filtered and solutions obtained from the filtration were diluted 
to $100 \mathrm{ml}$ with Millipore water. Aliquots of this solution were analyzed within the calibration conditions.

\section{Results and discussion}

\section{Cyclic voltammetry}

Electrochemical response of a solution having homogeneous mixture of $1.0 \mu \mathrm{M}$ of each AMP and MCP was estimated by cyclic voltammetry at $10 \mathrm{mV} \mathrm{s}^{-1}$ under optimized parameters using PTGPE. Anodic peaks for the oxidation of AMP and MCP were observed at $0.693 \mathrm{~V}$ and $1.123 \mathrm{~V}$, respectively, as shown in Fig. 1. Reduction peak is absent in the reverse sweep for both compounds which clearly indicates the irreversibility of the electrode reaction. The peak intensities for PTGPE are better compared to the peak intensities obtained by using bare GPE.

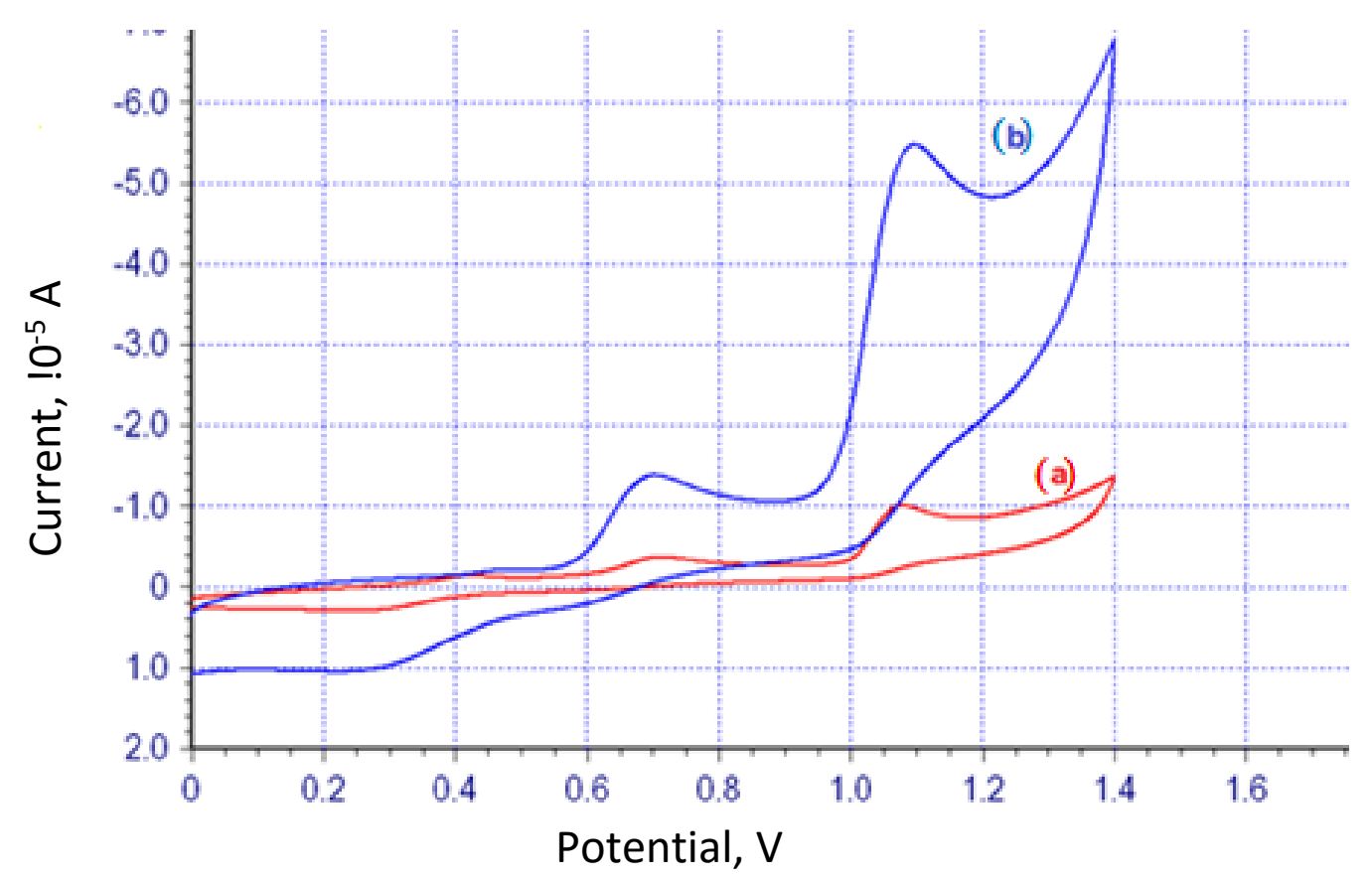

Fig. 1. Comparison of electrochemical behavior of mixture of $1 \mathrm{mM}$ of AMP and $1 \mathrm{mM}$ of MCP at (a) bare GPE, (b) PTGPE, with scan rate $10 \mathrm{mV} \mathrm{s}^{-1}$ at $\mathrm{pH} 4.2$.

\section{Effect of $\mathrm{pH}$}

The electro-oxidation of mixture of $1.0 \mu \mathrm{M}$ each of AMP and MCP was studied over the $\mathrm{pH}$ range of 3.0-8.0 in phosphate buffer solution by differential pulse voltammetry which is as shown in Fig. 2A. The $\mathrm{pH}$ of solution influenced the peak current [21-23]. The $\mathrm{pH}$ dependence of the peak potential when DPV was used is shown in Fig. 2B ( $\mathrm{a}$ and $\mathrm{b}$ ). With an increase in $\mathrm{pH}$ of the solution, peak potential shifted to less positive values and was found to obey the following equations:

$$
\begin{array}{ll}
E_{\mathrm{p}}=-0.0293 \mathrm{pH}+0.7214 ; & r=0.9821 \text { for } \mathrm{AMP} \\
E_{\mathrm{p}}=-0.0297 \mathrm{pH}+1.1483 ; & r=0.9615 \text { for } \mathrm{MCP}
\end{array}
$$

The best result with respect to sensitivity accompanied with sharper response and well separated peaks was obtained with $\mathrm{pH}=4.2$ (Fig. $2 \mathrm{C}$ ), and hence it was selected for further experiments. 


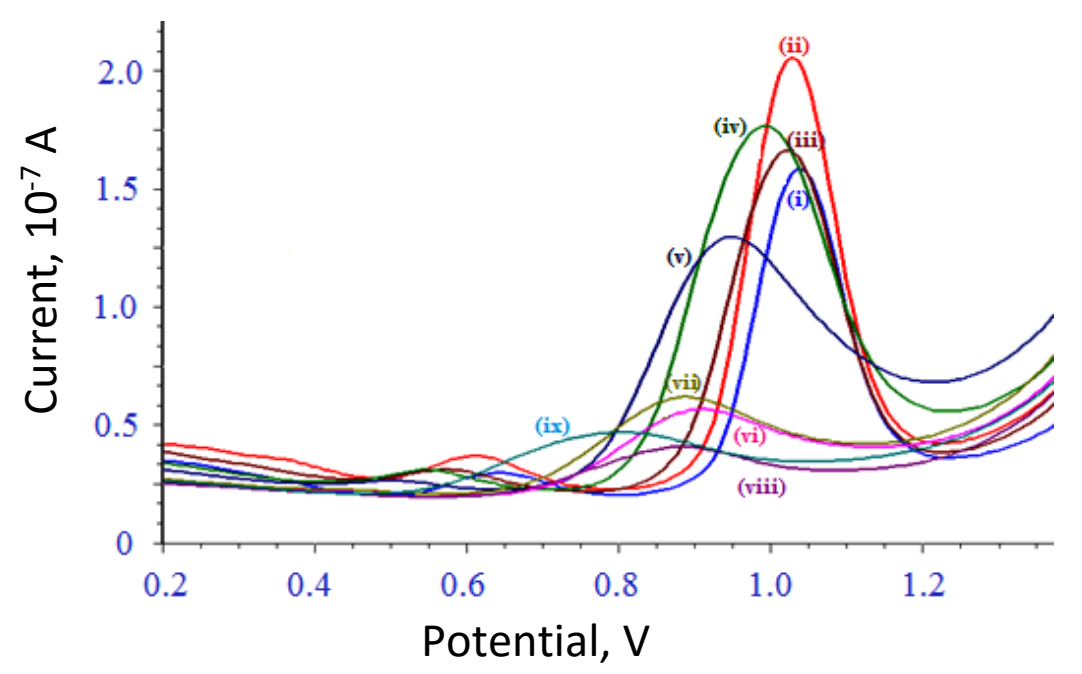

B
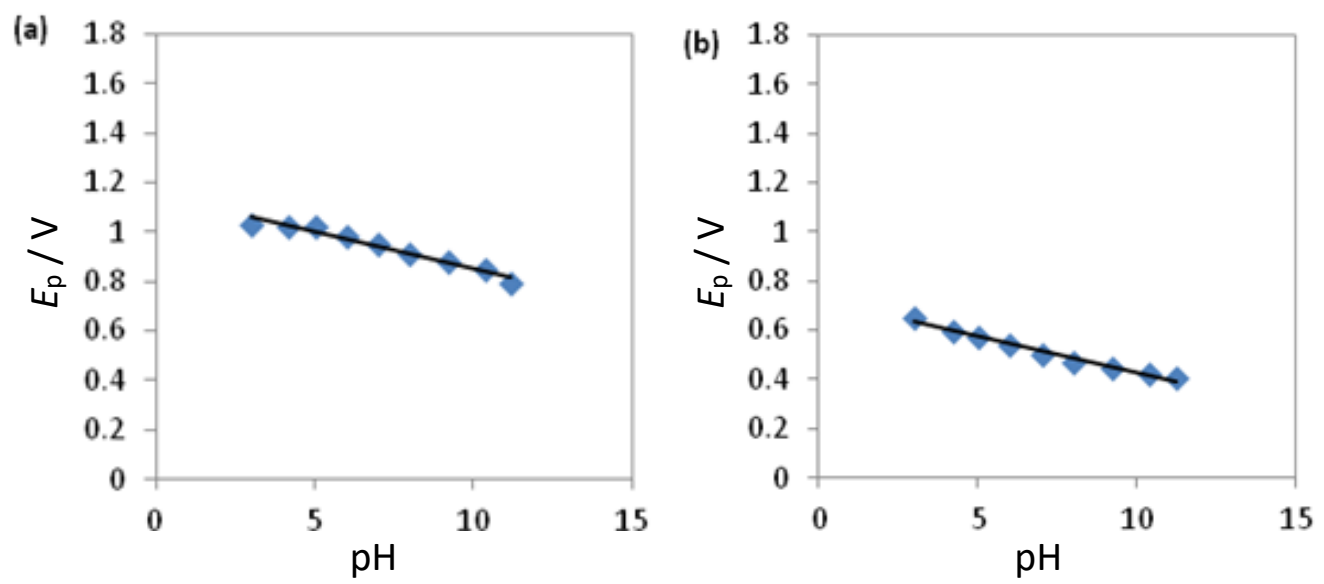

C

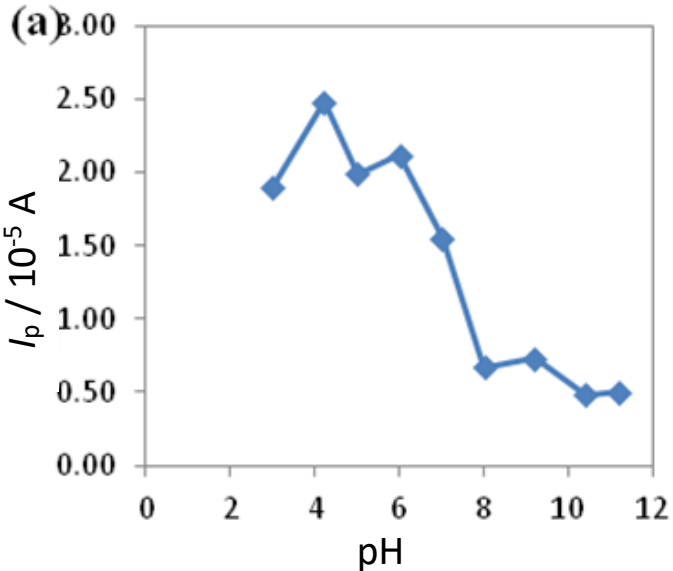

(b)

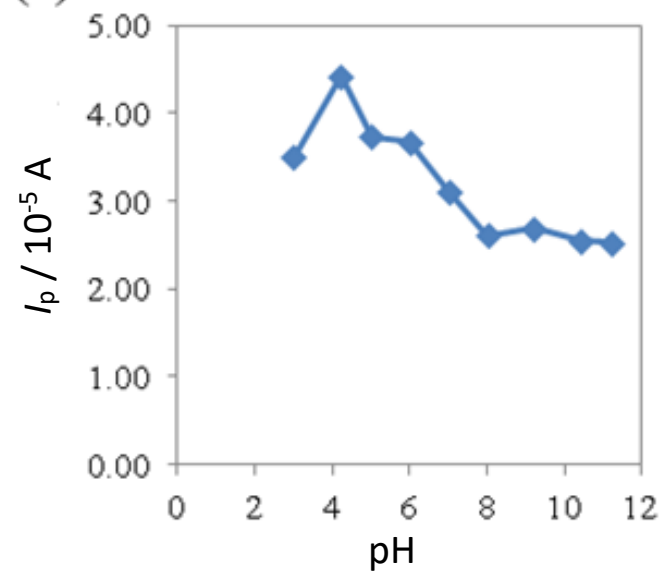

Fig. 2. A - dependence of $p H$ on the oxidation of mixture of $A M P$ and MCP at $p H$ (i) 3.0, (ii) 4.2, (iii) 5.0, (iv) 6.0, (v) 7.0, (vi) 8.0, (vii) 9.0, (viii) 10.4, (ix) 11.2; B - variation of peak potential with pH for (a) $1.0 \mu M M C P$ and (b) $1.0 \mu \mathrm{M} A M P$; $C$ - variation of peak current with $\mathrm{pH}$ for (a) $1.0 \mu \mathrm{M} \mathrm{MCP}$ and (b)1.0 $\mu \mathrm{M}$ AMP

\section{Effect of scan rate}

The effect of scan rate on the voltammetric oxidation of a mixture of AMP and MCP was examined by cyclic voltammetry between 10 to $190 \mathrm{mV} \mathrm{s}^{-1}$ (Fig. 3A). A linear relationship was observed between $\log I_{p}$ and $\log v$, (Fig. 3B) corresponding to the following equations:

A 


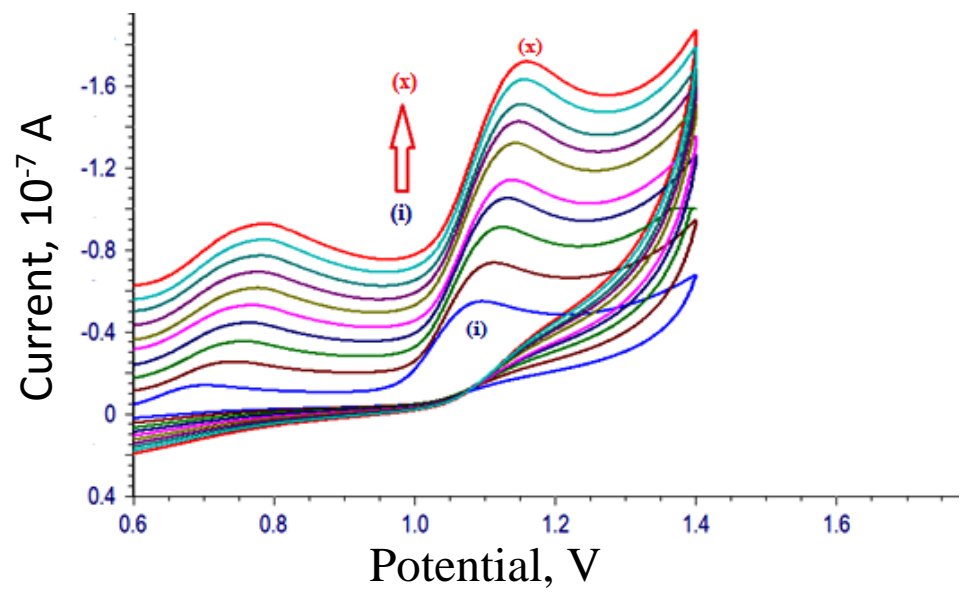

B
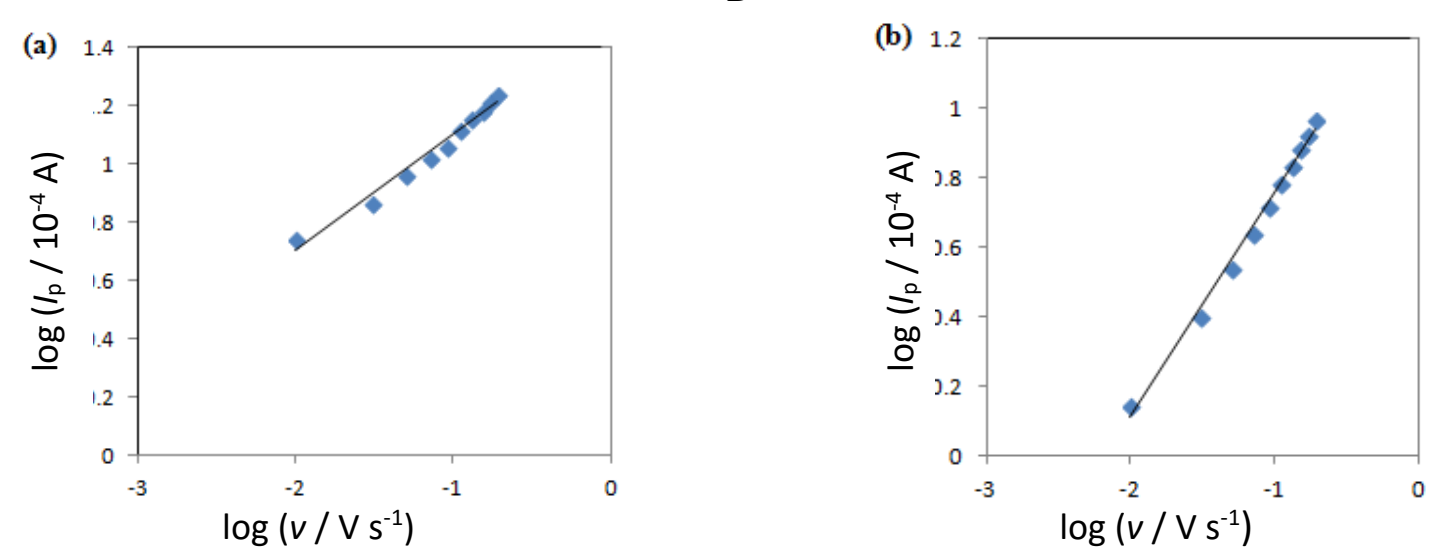

C
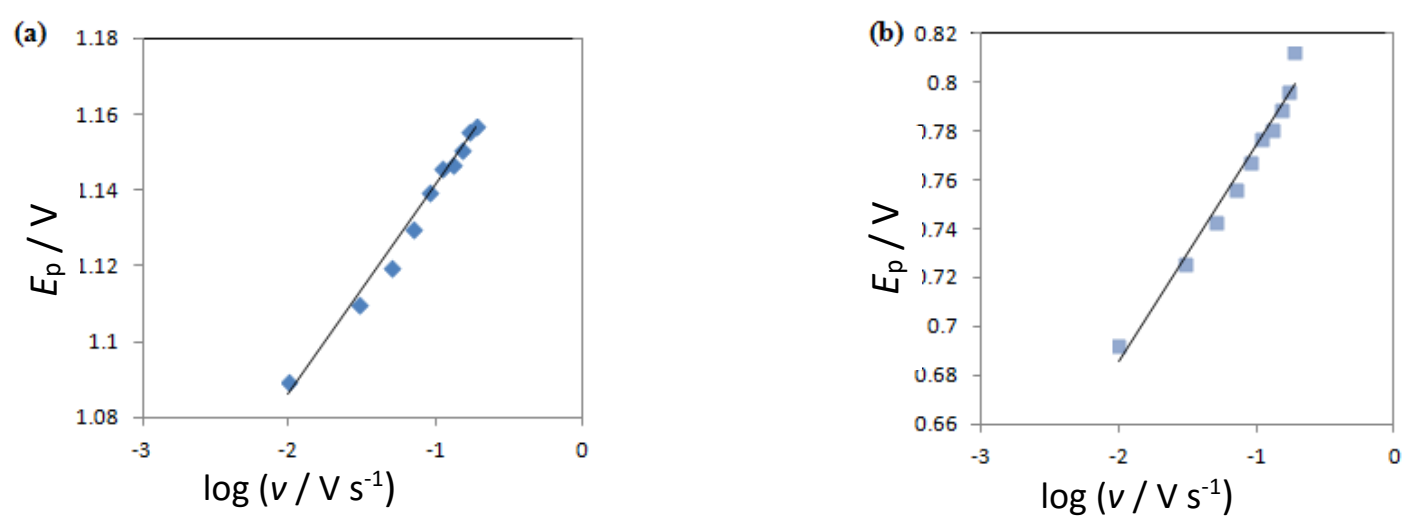

Fig. 3. $\boldsymbol{A}$ - Effect of scan rate on the electro-oxidation of a mixture of AMP and MCP. (i) 10,

(ii) 30, (iii) 50, (iv) 70, (v) 90, (vi) 110, (vii) 130, (viii) 150, (ix) 170, (x) $190 \mathrm{mV} \mathrm{s}-1$;

$B$ - observed dependence of peak current on the square root of scan rate for (a) MCP and (b) AMP;

$C$ - plot of variation of peak potential with logarithm of scan rate for (a) MCP and (b) AMP.

$\log I_{p}=0.6508 \log v+1.4111, \quad r=0.9942$ for AMP and

$\log I_{p}=0.3989 \log v+1.4981, \quad r=0.9796$ for MCP

The slopes of $0.65 \mathrm{~V} \mathrm{~s}^{-1}$ and $0.39 \mathrm{~V} \mathrm{~s}^{-1}$ were in the neighborhood of the theoretically expected value of $0.5 \mathrm{~V} \mathrm{~s}^{-1}$ for a purely diffusion controlled process [24] which, in turn, further confirms that the electro-oxidation of AMP and MCP were diffusion controlled. With an increase in scan rate, the peak potential shifted to a more positive value and a linear relationship was observed in the range 0.01 to $0.19 \mathrm{~V} \mathrm{~s}^{-1}$ as shown in Fig. $3 \mathrm{C}(\mathrm{a})$ and (b). The corresponding equations are expressed as:

$$
E_{\mathrm{p}}=0.0887 \log \mathrm{v}+0.8629, \quad r=0.9746 \text { for AMP and }
$$




$$
E_{\mathrm{p}}=0.0550 \log \mathrm{v}+1.1962, \quad r=0.9858 \text { for } \mathrm{MCP}
$$

For an irreversible electrode process, according to Laviron [25], $E_{\mathrm{p}}$ is defined by the following equation (2).

$$
E_{\mathrm{p}}=E^{0}+\frac{2.303 R T}{\alpha n F} \log \left(\frac{R T k^{0}}{\alpha n F}\right)+\left(\frac{2.303 R T}{\alpha n F}\right) \log v
$$

where $n$ is the number of electrons transferred, $v$ is the scan rate, $\alpha$ is the transfer coefficient, $k^{0}$ is the standard heterogeneous rate constant of the reaction and $E^{\prime}$ is the formal redox potential. Other symbols have their usual meanings. Thus the value of $\alpha$ nas easily calculated from the slope, and $k^{0}$ was calculated from the intercept of $E_{\mathrm{p}} v s$. $\log v$. $E^{0}$ was obtained from the intercept of $E_{\mathrm{p}} v s . v$ plot by extrapolating to the vertical axis at $v=0$ [24] Taking $T=298 \mathrm{~K}, R=8.314 \mathrm{~J} \mathrm{~K}^{-1} \mathrm{~mol}^{-1}$ and $F=96480 \mathrm{C} \mathrm{mol}^{-1}$, the transfer coefficient $(\alpha)$ and number of electrons transferred $(\mathrm{n})$ were calculated for both the drugs. The $\alpha$ value was calculated according to the Bard and Faulkner [26] equation (3).

$$
\alpha=\frac{47.7}{E_{\mathrm{p}}-E_{\mathrm{p} / 2}} \mathrm{mV}
$$

where $E_{\mathrm{p} / 2}$ is the potential when the current is at half the peak value. From this, the value of $\alpha$ was calculated to be 0.29 for AMP and 0.47 for MCP. Further, the number of electrons $(n)$ transferred in the electro-oxidation of AMP and MCP were calculated to be $2.1 \approx 2$ and $2.28 \approx 2.0$, respectively.

\section{Plausible mechanism}

Based on the experimental results, the number of electrons transferred $(n)$ for both the drugs were calculated to be two. Hence the probable electrooxidation mechanisms for both the drugs are proposed as given in Scheme 2, which are based on earlier works [27,28].

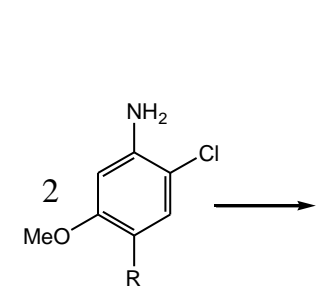<smiles>CCNC1C=C(Cl)C(=N)C=C1O</smiles><smiles>CC(=O)Nc1ccc(O)cc1</smiles><smiles>COC1=CC(=N)C(Cl)=CC1Nc1cc(OC)c(Br)cc1Cl</smiles><smiles>COc1cc(Nc2cc(Cl)c(N)cc2OC)c(Cl)cc1[18OH]</smiles>

Scheme 2. Proposed mechanisms for oxidation of (i) AMP and (ii) MCP 


\section{Analytical application}

To obtain an analytical curve for the sensor, quantitative analyses of the AMP and MCP concentrations were performed by DPV [29] at a PTGPE under the optimized experimental conditions. The oxidation of MCP occurs at high positive potential and there can be a chance of overlapping of MCP potential with the increasing concentration of drugs. Oxidation peak current was found to increase and no change in the peak current or potential of another drug indicates that these two drugs do not interact with each other. The peak current versus concentration of drug plots show a good linearity for AMP and MCP in certain concentration ranges as depicted in Fig. 4A and $B$. Peak current values were obtained by subtracting the background current of PBS and average of three replicate measurements were used to plot calibration curves. Linear regression equations for both the drugs arising from calibration plots are represented as:

$$
\begin{array}{ll}
I_{\mathrm{p}}=0.212 C+0.344, & r=0.9703 \text { for AMP } \\
I_{\mathrm{p}}=0.928 C+1.257, & r=0.9767 \text { for MCP }
\end{array}
$$

A

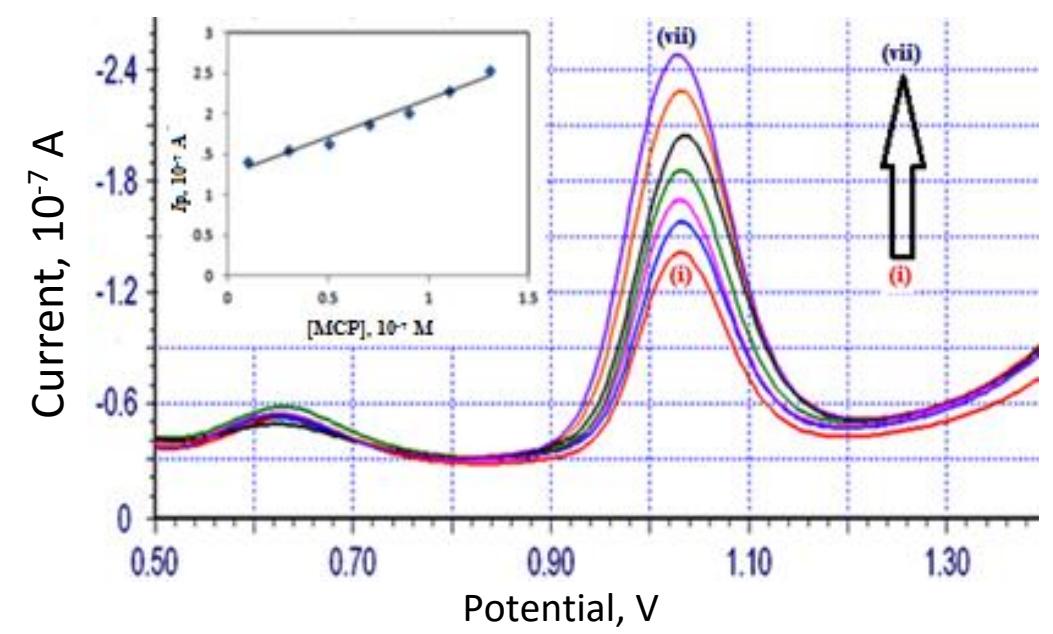

B

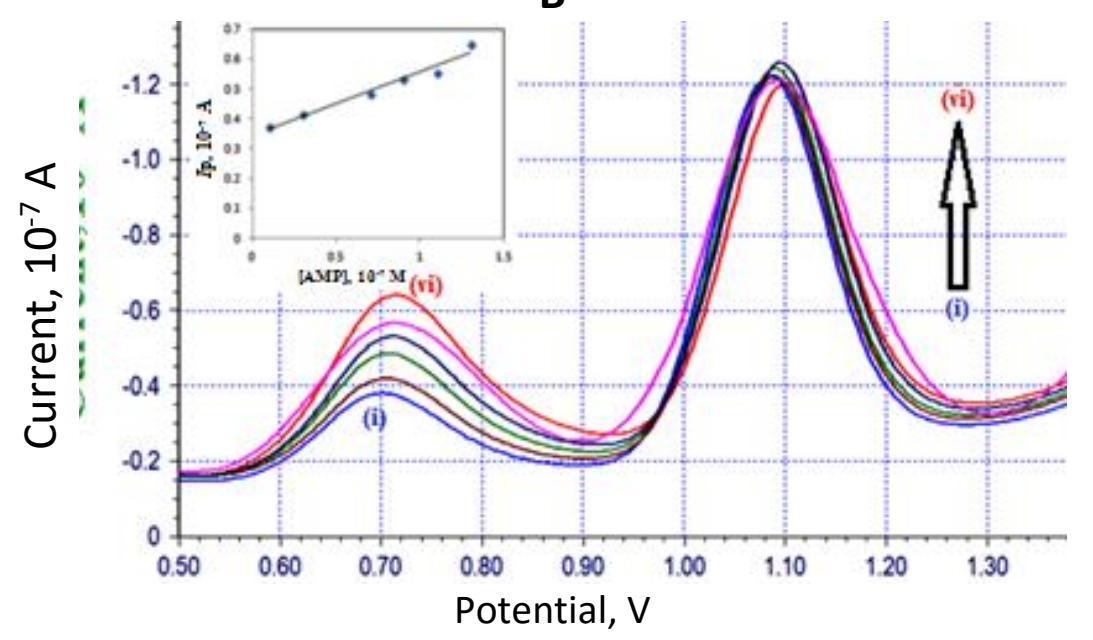

Fig. 4. A - differential pulse voltammograms for increasing concentration of MCP at PTGPE (i) 1, (ii) 3, (iii) 5, (iv) 7, (v) 9, (vi) 11, (vii) 13, 10-7 M with AMP concentration $1 \times 10^{-6} \mathrm{M}$; $\boldsymbol{B}$ - differential pulse voltammograms for increasing concentration of AMP at PTGPE (i) 1, (ii) 3, (iii) 7, (iv) 9, (v) 11, (vi) 13, 10-7 M with MCP concentration $1 \times 10^{-7} \mathrm{M}$.

The limit of detection (LOD) and limit of quantification (LOQ) were calculated by using the formulae $L O D=3 s / m$ and $L O Q=10 s / m$, where $s$ is the standard deviation of peak current and $m$ is 
the slope of calibration curves. LODs were found to be $3.25 \times 10^{-9} \mathrm{M}$ and $1.16 \times 10^{-9} \mathrm{M}$ for AMP and MCP respectively and the LOQs were calculated as $10.84 \times 10^{-9} \mathrm{M}$ and $3.88 \times 10^{-9} \mathrm{M}$, respectively. Since, it is important to calculate validation parameters for any analytical method, the calibration characteristics obtained for MCP and AMP are given in Table 1.

Table 1. The calibration characteristics for metoclopramide and acetaminophen at PTGPE.

\begin{tabular}{lcc}
\hline & MCP & AMP \\
\hline Linearity range, $10^{-7} \mathrm{M}$ & $0.1-1.1$ & $0.1-1.1$ \\
\hline Slope of the calibration plot & 0.928 & 0.212 \\
\hline Intercept & 1.275 & 0.344 \\
\hline Correlation coefficient $(r)$ & 0.9767 & 0.9703 \\
\hline RSD of slope, $\%$ & 1.21 & 0.82 \\
\hline RSD of intercept, \% & 0.12 & 0.65 \\
\hline Number of data points & 5 & 5 \\
\hline LOD, nM & 1.16 & 3.25 \\
\hline LOQ, nM & 3.88 & 10.84 \\
\hline Repeatability of peak current, \% & 0.79 & 1.14 \\
\hline Repeatability of peak potential, \% & 0.51 & 0.35 \\
\hline Reproducibility of peak current, \% & 0.92 & 0.71 \\
\hline Reproducibility of peak potential, \% & 0.24 & 0.43 \\
\hline
\end{tabular}

The precision of the method was calculated by repeating five experiments on the same day in standard conditions (repeatability) and over two days from the different standard solutions (reproducibility). For these studies $1.0 \times 10^{-6} \mathrm{M}$ of each of AMP and MCP standard solutions were used. From RSD values of peak potential and peak current between day reproducibility were similar to that of within a day if the temperature was kept almost unchanged which shows the excellent stability and reproducibility of PTGPE.

\section{Effect of excipients}

The effect of some common excipients used commonly in pharmaceutical preparations was examined. The tolerance limit was defined as the maximum concentration of the interfering substance that caused less than $5 \%$ error for the determination of AMP and MCP. The effects of these excipients on the voltammetric response were obtained by analyzing sample solutions containing a fixed amount of AMP and MCP $\left(1.0 \times 10^{-6} \mathrm{M}\right)$ spiked with various amounts of each excipient under the same experimental conditions. The experimental results showed that a hundred-fold excess of gum acacia, citric acid, dextrose, glucose, lactose, tartaric acid and sucrose did not interfere with the voltammetric signal of AMP and MCP. Hence, these compounds need not be extracted from these tablet additives prior to their determination in tablets.

\section{Detection of $A M P$ and $M C P$ in human urine samples}

The developed DPV method for the AMP and MCP determination was applied to human urine samples. The recoveries from urine were measured by spiking drug free urine with known amounts of AMP and MCP. The urine samples were diluted 100 times with the PBS before analysis without further pretreatment. A quantitative analysis was carried out by adding the standard solutions of AMP and MCP into the detection system of urine samples. The peak current increased linearly in height. The calibration plot was used for the determination of spiked AMP and MCP in urine samples. The results of four urine samples obtained are listed in Table 2. Thus, satisfactory 
recoveries of the analytes from the real samples were in a good agreement with the concentration ranges studied and the real ranges encountered in the urine samples when treated with drug, make the developed method applicable in clinical analysis.

Table 2. Results of analysis of metoclopramide and acetaminophen in spiked urine samples

\begin{tabular}{cccc}
\hline MCP added, $10^{-8} \mathrm{M}$ & Quantity found ${ }^{(\mathrm{a}),} 10^{-8} \mathrm{M}$ & Average recovery, $\%$ & RSD $^{\mathrm{a}}, \%$ \\
\hline 10 & \multicolumn{3}{c}{ Metoclopramide } \\
15 & 9.7 & 97.0 & 1.91 \\
20 & 14.5 & 96.6 & 2.20 \\
25 & 19.2 & 96.0 & 2.12 \\
30 & 24.6 & 98.2 & 2.66 \\
35 & 29.6 & 98.8 & 1.59 \\
& 34.2 & 97.4 & 2.21 \\
10 & & Acetaminophen & \\
15 & 9.5 & 95.0 & 1.83 \\
20 & 14.9 & 99.5 & 1.24 \\
30 & 20.1 & 100.5 & 2.62 \\
35 & 24.4 & 97.6 & 2.31 \\
\hline
\end{tabular}

a -average of five determinations

\section{Determination of AMP and MCP in pharmaceutical samples}

This method was applied for the determination of AMP and MCP in tablets. As shown in Table 3, the content of AMP and MCP was calculated to be $495.1 \mathrm{mg} /$ tablet (the nominal content is $500 \mathrm{mg} /$ tablet) and $9.7 \mathrm{mg} /$ tablet (the nominal content is $10 \mathrm{mg} /$ tablet) respectively. To validate and obtain the accuracy and precision of the developed method, recovery studies were performed at different drug concentrations by the standard addition method. For the present study, known quantities of AMP and MCP were mixed separately with definite amounts of pre-analyzed formulations and mixtures were analyzed as before. Table 3 shows the measurement results, and the average recovery was found to be $99.02 \%$ and $97.0 \%$ for AMP and MCP respectively. The F and Student $t$ tests were also calculated with confidential level of $95 \%$ and are shown in Table 3.

Table 3. Results of analysis of tablet containing both the analytes (acetaminophen $500 \mathrm{mg}$ and metoclopramide $10 \mathrm{mg}$ ) in commercially available tablet samples by DPV

\begin{tabular}{lcc}
\hline & Acetaminophen & Metoclopramide \\
\hline Labeled claim, mg & 500.00 & 10.00 \\
Quantity found, mg & 495.10 & 9.70 \\
Recovery ${ }^{\text {a } \%}$ & 99.02 & 97.00 \\
RSD $^{\text {a } \%}$ & 1.92 & 2.31 \\
$t$ - value at 95\% confidence level & 0.16 & 0.21 \\
-value at 95\% confidence level & 1.47 & 1.76 \\
\hline
\end{tabular}

a -average of five determinations

\section{Conclusion}

The pre-treated pencil graphite electrode was applied successfully as a sensor for fast, accurate and simultaneous determination of AMP and MCP in some pharmaceutical samples. The present method is a good alternative for the analytical determination of AMP and MCP simultaneously, because it is simple, sensitive, accurate, fast, and inexpensive. The results were successfully applied 
in urine samples and pharmaceuticals. Furthermore, the present method could possibly be employed for pharmacokinetic studies and also in clinical and quality control laboratories.

Acknowledgement: The author thanks the UGC, New Delhi for the award of UGC-BSR faculty fellowship to Dr. S. T. N.

\section{References}

[1] J. I. Gowda, S.T.Nandibewoor, Anal. Methods 6 (2014) 5147-5154.

[2] E. Alipour, S. Gasemlou, Anal. Methods 4 (2012) 2962-2969.

[3] I. Parlak, R. Atilla, M. Cicek, M. Parlak, B. Erdur, M. Guryay, M. Sever, S. Karaduman, Emerg. Med. J. 22 (2005) 621-624.

[4] P. Norouzi, M. R. Ganjali, P. Matloobi, Electrochem. Commun. 7 (2005) 333-338.

[5] C. P. Page, M. J. Curtis, M. C. Sutter, M. J. A. Walker, B. B. Hoffman, Farmacología Integrada, Ed. Harcourt. España. 1998.

[6] L. J. Roberts, J. D. Morrow, in: The Pharmacological Basis of Therapeutics, 10th ed., J. G. Hardman, L. E. Limbird, A. G. Gilman (Eds.), McGraw-Hill, London, 2001.

[7] R. V. Blanke, W. J. Decker, in: Textbook of Clinical Chemistry, N.W. Tietz (Ed.), W.B. Saunders, Philadelphia, 1986.

[8] D. Gunnell, V. Murray, K. Hawton, Suicide Life Threat. Behav. 30 (2000) 313-326.

[9] W. A. Martindale, The Extra Pharmacopoeia, $27^{\text {th }}$ ed., The Pharmaceutical Press, London, 1979.

[10] B. D. Clayton, Y. N. Stock, Basic Pharmacology for Nurses, Mosby Inc, Harcourt Health Sciences Company, St. Louis, Mo, USA, 2001.

[11] N. Wangfuengkanagul, O. Chailapakul, J. Pharm. Biomed. Anal. 28 (2002) 841-847.

[12] J. I. Gowda, D. G. Gunjiganvi, N. B. Sunagar, M. N. Bhat, S. T. Nandibewoor, RSC Adv. 5 (2015) 49045-49053.

[13] S. M. Patil, S. T. Nandibewoor, Anal. Bioanal. Electrochem. 7 (2015) 387-400.

[14] S. J.Wadher, P. R.Pathankar, M. Puranik, R.O. Ganjiwale, P. G. Yeole, Ind. J. Pharm. Sci.70 (2008) 393-395.

[15] A. E. El-Aleem, S. M. Khalile, A. M. Badawy, O. K. El-Naggar. Research J. Pharma. Dosage Forms and Tech. 5 (2013) 270-274.

[16] G. Shubhangee, K. Manish, N. Swapnil, Int. J. Pharm. Li. Sci, 1 (2010) 127-132.

[17] N. P. Dudhane, S. S.Vidhate. B. H.Borkar, R. T. Lohiya, M. J. Umekar, J. Pharm. Sci. \& Res. 2 (2010) 48-52.

[18] G. Vamshikrishna, M. Neelima, M. Bhavani, G,Sreekanth, S. Shobha Rani. IOSR J. Pharm. Bio. Sci. 9 (201) 69-78.

[19] G. D. Christian, W. C. Purdy, J. Electroanal. Chem. 3 (1962) 363-367.

[20] B. Rezaei, S. Damiri, Sens. Actuators B, 134 (2008) 324-331.

[21] B. D. Topal, B. Bozal, B. T. Demircigil, B. Ulsu, S.A. Ozkan, Electroanalysis. 21 (2009) 24272439.

[22] J. Wang, Electroanalytical Techniques in Clinical Chemistry and Laboratory Medicine; VCH: New York, 1988.

[23] P. T. Kissinger, W. R. Heineman, Laboratory Techniques in Electroanalytical Chemistry, $2^{\text {nd }}$ ed.; Marcel Dekker: New York, 1996.

[24] D. K. Gosser, Cyclic Voltammetry: Simulation and Analysis of Reaction Mechanisms, VCH, New York, 1993.

[25] E. Laviron, J. Electroanal. Chem. 101 (1979) 19-21.

[26] J. Bard, L. R. Faulkner, Electrochemical Methods Fundamentals and Applications, Wiley, $2^{\text {nd }}$ ed, 2004, 
[27] B. Habibi, M. Jahanbakhshi, M. H. Pournaghi-Azar, Analytical Biochemistry. 411 (2011) 167175.

[28] S. Shahrokhian, L. Naderi and M. Ghalkhani, Electroanalysis 27 (2015) 2637 - 2644.

[29] N. L. Teradal, S. N. Prashanth, J. Seetharamappa, J. Electrochem. Sci. Eng. 2 (2012) 67-75. 